\title{
Profile of capecitabine/temozolomide combination in the treatment of well-differentiated neuroendocrine tumors
}

This article was published in the following Dove Press journal:

OncoTargets and Therapy

9 February 2016

Number of times this article has been viewed

Elias A Kotteas'

Konstantinos N Syrigos ${ }^{1,2}$

Muhammad Wasif Saif ${ }^{3}$

'Oncology Unit, Sotiria General Hospital, University of Athens,

Athens, Greece; ${ }^{2}$ Thoracic Oncology Program, Yale School of Medicine, New Haven, CT, USA; ${ }^{3}$ Section of $\mathrm{GI}$ and Experimental Therapeutics, Tufts University School of Medicine, Boston, MA, USA
Correspondence: Muhammad Wasif Saif Section of Gl and Experimental Therapeutics, Tufts University School of Medicine, 800 Washington Street, Boston, MA 02III, USA

Tel +l 6176368077

Email wsaif@tuftsmedicalcenter.org
Abstract: Neuroendocrine tumors are a rare and heterogeneous group of tumors with a variety of primary origins and variable aggressiveness. Platinum-based chemotherapy has been the cornerstone of treatment for the poorly differentiated tumors. However, well-differentiated neuroendocrine tumors are quite chemoresistant and therapy options are limited. Octreotide analogs and tyrosine kinase inhibitors are widely acceptable treatments due to substantial efficacy and tolerable toxicity. On the contrary, monotherapy or combinations of the only approved cytotoxic agent streptozocin with other drugs have been almost abandoned because of excessive toxic events. In recent years, the combination of capecitabine and temozolomide has emerged as the most promising and efficacious treatment. The oral route of administration and the substantial improvement in the outcomes with manageable toxicity are the major advantages. We reviewed the current literature and presented the profile of the capecitabine/temozolomide combination in the management of well-differentiated neuroendocrine tumors.

Keywords: capecitabine, neuroendocrine tumors, octreotide analogs, streptozocin, temozolomide, toxicity

\section{Introduction}

Initially identified in 1907, neuroendocrine tumors (NETs) still represent a heterogeneous group of poorly understood rare malignancies with varying behavior. Advances in diagnostic imaging and endoscopy revealed an increased incidence of these tumors in the last 15 years accounting for $\sim 0.5 \%$ of all bronchopulmonary and gastrointestinal (GI) cancers. Sixty percent of NETs have been found in the GI tract (predominantly small bowel or pancreas). According to the World Health Organization 2010, NETs are classified as well differentiated (grade 1/low and grade 2/intermediate). Grade 3/poorly differentiated tumors are classified as neuroendocrine carcinomas (NECs) (Table 1). Well-differentiated NETs are further classified as functioning or nonfunctioning tumors depending on hormonal secretion. They demonstrate an indolent and commonly asymptomatic course resulting in a delayed diagnosis. As a consequence, $20 \%$ of grade 1 and $30 \%$ of grade 2 tumors have distant metastases at diagnosis. On the other hand, NECs are aggressive, such as small cell carcinoma. ${ }^{1,2}$ Synchronous disseminated disease is documented at diagnosis in $50 \%$ of NECs. Somatostatin analogs octreotide and lanreotide provided the ability to control symptoms and tumor growth with a reflected prolongation in progression-free survival (PFS) of 8 months compared with placebo in well-differentiated NETs of GI origin. ${ }^{3,4}$ Tyrosine kinase (sunitinib) and mammalian target of rapamycin inhibitors (everolimus) have also shown a benefit in terms of PFS of 7 months compared with placebo in pancreatic low and intermediate 
Table I Neuroendocrine tumors classification

\begin{tabular}{lllll}
\hline Differentiation & Grade & ki-67 (\%) & Mitotic rate (HPF) & Classification \\
\hline Well differentiated & GI - low grade & $<3$ & $<2 / 10$ & Neuroendocrine tumor \\
Well differentiated & G2 - intermediate grade & $3-20$ & $2-10 / 10$ & Neuroendocrine tumor \\
Poorly differentiated & G3 - high grade & $>20$ & $>20 / 10$ & Neuroendocrine carcinoma \\
\hline
\end{tabular}

Abbreviation: HPF, high power field.

differentiated NETs (pNETs) ${ }^{5,6}$ The role of chemotherapy in the metastatic setting of well-differentiated NETs is unclear and controversial. Platinum salt combinations with etoposide or irinotecan have an established place in the treatment of NECs. However, chemotherapy for the slow-growing, welldifferentiated NETs has failed to achieve acceptance due to either limited efficacy or excessive toxicity. Streptozocin is the only approved agent for the treatment of islet-cell pancreatic tumors since 1982. Several retrospective trials reported objective response rates (ORR) between 6\% and $42 \%$ of streptozocin combinations with doxorubicin and/or 5-fluorouracil (5-FU) in pNETs, but with a substantial risk of grade 3 and 4 toxicities of $25 \%$, which in many cases has led to a treatment discontinuation. ${ }^{7-10}$ Taking into account that unresectable NETs carry a dismal prognosis with a median survival of 24 months, ${ }^{1}$ several studies have aimed at the incorporation of new cytotoxic agents with lesser toxicity, but with significant efficacy in the treatment of metastatic NETs. In the last years, the combination of capecitabine and temozolomide (Cap/Tem) has gained increased interest given the feasibility of oral administration with limited toxicity and particularly promising ORR. This review article encompasses the accumulating body of evidence regarding the efficacy of the Cap/Tem regimen in the well-differentiated NETs.

\section{Rationale for Cap/Tem combination}

Capecitabine is a prodrug of the pyrimidine analog 5-FU, which is enzymatically converted to 5-FU. 5-FU as a thymidylate synthase inhibitor impacts DNA synthesis. Capecitabine monotherapy has demonstrated PFS of 9.9 and 15.5 months in a few small trials of GI NETs. ${ }^{11,12}$ Capecitabine combined with streptozocin reached a PFS of 10.2 months. However, a $44 \%$ of grade 3 and 4 adverse events was described and attributed mainly to streptozocin. ${ }^{13}$ Temozolomide is an imidazotetrazine derivative of the alkylating agent dacarbazine. Dacarbazine's efficiency against pancreatic NETs was described almost 20 years ago. ${ }^{14}$ Temozolomide methylates DNA, which leads to tumor cell death. As single therapy in pretreated NETs, it has offered PFS of 3.5 and 7 months and ORR of $0 \%-14 \% .{ }^{15}$ A Phase II trial of temozolomide and thalidomide offered a median PFS of 13.5 months. Again toxicity was not acceptable with $69 \%$ of patients developing grade 3 and 4 side effects. ${ }^{16}$ From all these trials, tumors with lowest ki-67 expression and non-pNETs, proved more resistant to chemotherapy. The pharmacologic rationale for Cap/Tem emerged from the hypothesis that slow-growing NETs might be more sensitive to cytotoxic drugs that have an extended $\mathrm{G}_{0}$ phase cycle. Consequently, a lipophilic methylator such as temozolomide under continuous exposure to an antimetabolite such as capecitabine could be beneficial. In vitro, concurrent administration of both drugs from day 1 resulted in additional toxicity and not synergy. Nevertheless, $\mathrm{Cap} / \mathrm{Tem}$ was found to be maximum synergistic if 5-FU administration preceded temozolomide by 9 days. The reason for this synergy could be attributed to $\mathrm{O}_{6}$-methylguanine DNA methyltransferase (MGMT). High expression of the MGMT DNA repair enzyme is associated with cancer cell resistance to alkylating agents such as temozolomide. Glioma patients with low MGMT expression due to MGMT gene inactivation through promoter methylation have better survival when treated with temozolomide compared with those whose tumors express high MGMT levels. ${ }^{17,18}$ In the case of NETs, the initial single capecitabine administration for 9 days seems to cause the depletion of the MGMT gene, which makes the NETs chemosensitive to temozolomide at day 10. The Cap/Tem regimen schedule includes capecitabine administration of $600-1,000 \mathrm{mg} / \mathrm{m}^{2}$ bid on days $1-14$ and temozolomide $150-200 \mathrm{mg} / \mathrm{m}^{2}$ on days $10-14$ on two divided daily doses (Figure 1). Divided dosing of temozolomide is supported by in vitro data. Methyl groups from the $\mathrm{O}_{6}$ position on guanine are typically removed by $\mathrm{O}_{6}$-MGMT. The first dose causes partial depletion of MGMT levels, whereas the second dose is responsible for the methylation of guanines with decreased repair from $\mathrm{O}_{6}$-MGMT. ${ }^{19,20}$

\section{Cap/Tem responses and outcomes}

We present the data from seven studies of a retrospective nature since prospective trials are not feasible due to the rarity of NETs (Table 2). ${ }^{17,21-28}$

The majority of cases are from a pancreatic primary. It should be mentioned that in all these studies with the exception of one, targeted therapies were not administered. 


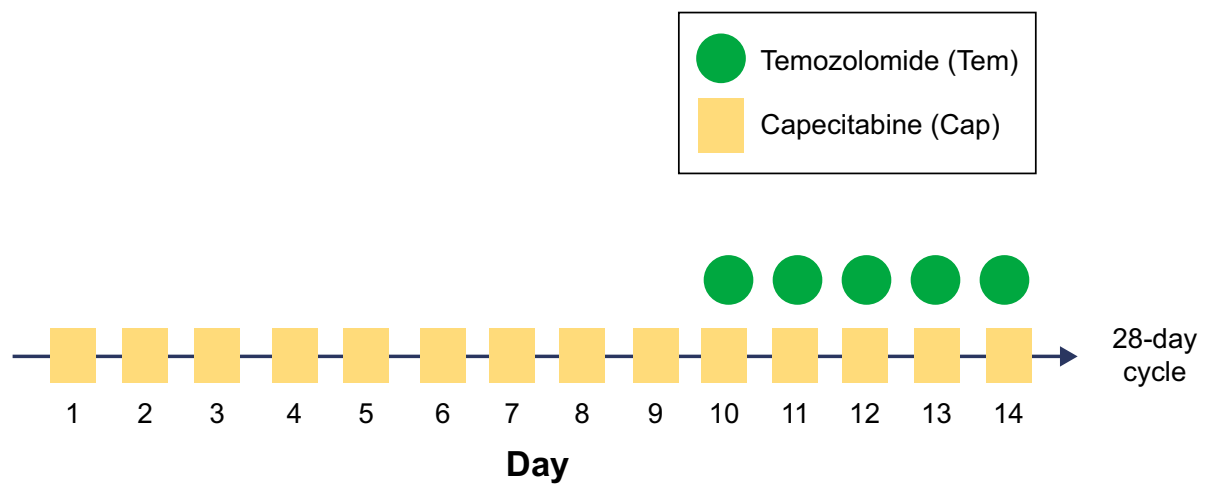

Figure I Cap/Tem schedule.

Table 2 Response rates and outcomes

\begin{tabular}{|c|c|c|c|c|c|c|c|}
\hline Study & Primary & Patients, $\mathbf{n}$ & $\begin{array}{l}\text { Prior } \\
\text { treatment }\end{array}$ & $\begin{array}{l}\text { Cap/Tem } \\
\text { doses }\left(\mathrm{mg} / \mathrm{m}^{2}\right)\end{array}$ & $\begin{array}{l}\text { Responses } \\
\text { (\%) }\end{array}$ & $\begin{array}{l}\text { Median PFS } \\
\text { (months) }\end{array}$ & $\begin{array}{l}\text { Median OS } \\
\text { (months) }\end{array}$ \\
\hline Fine et $\mathrm{al}^{17}$ & Metastatic NETs & 10 & $\begin{array}{l}\text { Octreotide } \\
\text { Chemotherapy }\end{array}$ & $\begin{array}{l}\text { Cap: } 750 \\
\text { Tem: } 150-200\end{array}$ & $\begin{array}{l}\text { CR: } 16 \\
\text { PR: } 34 \\
\text { SD: } 50\end{array}$ & NR & $>18$ for $C R$ \\
\hline $\begin{array}{l}\text { Strosberg } \\
\text { et } \mathrm{al}^{21}\end{array}$ & Pancreas (100\%) & 30 & $\begin{array}{l}\text { Local therapies } \\
\text { Octreotide }\end{array}$ & $\begin{array}{l}\text { Cap: } 750 \\
\text { Tem: } 200\end{array}$ & $\begin{array}{l}\text { PR: } 70 \\
\text { SD: } 30 \\
\text { PD: } 3\end{array}$ & 18 & $\begin{array}{l}92 \% 2 \text {-year } \\
\text { survival }\end{array}$ \\
\hline Fine et $\mathrm{al}^{22}$ & $\begin{array}{l}\text { Pancreas (50\%) } \\
\text { Carcinoids } \\
\text { MENI } \\
\text { Gastrinoma } \\
\text { Glucagonoma }\end{array}$ & 18 & $\begin{array}{l}\text { Octreotide } \\
\text { Chemotherapy } \\
\text { Chemoem- } \\
\text { bolization }\end{array}$ & $\begin{array}{l}\text { Cap: } 600 \\
\text { Tem: } 150-200\end{array}$ & $\begin{array}{l}\text { CR: } 5.5 \\
\text { PR: } 55.5 \\
\text { SD: } 22.2\end{array}$ & 14 & 83 \\
\hline Saif et $\mathrm{a}^{23}$ & Pancreas (100\%) & 7 & $\begin{array}{l}\text { Octreotide } \\
\text { Local therapies } \\
\text { Chemotherapy }\end{array}$ & $\begin{array}{l}\text { Cap: I,000 } \\
\text { Tem: } 200\end{array}$ & $\begin{array}{l}\text { PR: } 43 \\
\text { SD: } 28 \\
\text { PD: } 29\end{array}$ & 12 & 24 \\
\hline Fine et $\mathrm{al}^{24}$ & $\begin{array}{l}\text { Pancreas } \\
\text { Typical and atypical carcinoids } \\
\text { Pituitary gland } \\
\text { Thyroid gland (medullary } \\
\text { tumors) }\end{array}$ & 28 & Octreotide & $\begin{array}{l}\text { Cap: } 750 \\
\text { Tem: } 150-200\end{array}$ & $\begin{array}{l}\text { CR: II } \\
\text { PR: } 32 \\
\text { SD: } 54 \\
\text { PD: } 3\end{array}$ & $>22$ & $>29$ \\
\hline $\begin{array}{l}\text { Peixoto } \\
\text { et } \mathrm{al}^{25}\end{array}$ & $\begin{array}{l}\text { Pancreas (48\%) } \\
\text { Small bowel } \\
\text { Lung } \\
\text { Rectum } \\
\text { Appendix } \\
\text { Unknown }\end{array}$ & 29 & $\begin{array}{l}\text { Octreotide } \\
\text { Local therapies } \\
\text { Chemotherapy } \\
\text { Targeted } \\
\text { therapy }\end{array}$ & $\begin{array}{l}\text { Cap: } 750 \\
\text { Tem: } 200\end{array}$ & NR & 4.7 & 20.2 \\
\hline $\begin{array}{l}\text { Abbasi } \\
\text { et } \mathrm{al}^{26}\end{array}$ & $\begin{array}{l}\text { Pancreas }(67 \%) \\
\text { Rectum } \\
\text { Colon } \\
\text { Stomach }\end{array}$ & 21 & $\begin{array}{l}\text { Octreotide } \\
\text { Chemotherapy } \\
\text { Local therapies }\end{array}$ & $\begin{array}{l}\text { Cap: } 600 \\
\text { Tem: } 50 / 200\end{array}$ & $\begin{array}{l}\text { PR: } 57 \\
\text { SD: } 23 \\
\text { PD: } 20\end{array}$ & 16.5 & NR \\
\hline Spada et a ${ }^{28}$ & $\begin{array}{l}\text { Pancreas }(55 \%) \\
\text { Gastrointestinal unknown } \\
\text { Lung } \\
\text { NEC (7) }\end{array}$ & 58 & $\begin{array}{l}\text { Octreotide } \\
\text { Chemotherapy }\end{array}$ & $\begin{array}{l}\text { Cap: } 1,500 \\
\text { Tem: } 150-200\end{array}$ & $\begin{array}{l}\text { PR: } 22 \\
\text { SD: } 52 \\
\text { PD: } 23\end{array}$ & 13 & 41.5 \\
\hline $\begin{array}{l}\text { Ramirez } \\
\text { et } \mathrm{a}^{27}\end{array}$ & $\begin{array}{l}\text { Pancreas (50\%) } \\
\text { Small bowel } \\
\text { Lung } \\
\text { Rectum } \\
\text { NEC (4) }\end{array}$ & 30 & NR & NR & $\begin{array}{l}\text { PR: } 33 \\
\text { SD: } 40 \\
\text { PD: } 27\end{array}$ & 11 & NR \\
\hline
\end{tabular}

Abbreviations: Cap, capecitabine; CR, complete response; NEC, neuroendocrine carcinoma; NR, not reported; PD, progressive disease; PR, partial response; SD, stable disease; Tem, temozolomide; PFS, progression-free survival; OS, overall survival; NETs, neuroendocrine tumors; MENI, multiple endocrine neoplasia type I. 
Patients were treated with octreotide analogs, local interventions, and cytotoxic regimens. Treatment with $\mathrm{Cap} / \mathrm{Tem}$ in pNETs produced better objective response rates and disease control rates (DCR) than in patients with non-pNETs. In pNETs, ORR of $43 \%-70 \%$ were reported corresponding to a clinical benefit of 12-18 months in terms of PFS. Almost all patients with pNETs demonstrated very impressive DCR (70\%-97\%). The highest responses were seen in patients with no prior chemotherapy. Cap/Tem proved to be less effective in heavily pretreated patients with pNETs. In one study where prior treatment included chemotherapy and targeted therapy, PFS was 3.1 months. ${ }^{25}$ In non-pNETs including NETs from rectum, stomach, typical or atypical lung carcinoids, ORR and DCR were lower compared with pNETs $(33 \%-42 \%$ and 56\%-64\%, respectively), but still particularly significant. Nevertheless, PFS in a small number of non-pNETs cases has been reported between 10.5 and 22 months. Median overall survival (OS) for all patients was between 20.2 and 83 months. Two-year OS exceeded $92 \%$.

\section{Toxicities}

The most common grade 3 or 4 hematological adverse events were thrombocytopenia (3\%-12\%) and lymphopenia (35\%). Grade 1 or 2 neutropenia was $\sim 50 \%$. One patient had pancytopenia. No opportunistic infections were reported. Concerning nonhematologic side effects, grade 1 or 2 palmar-plantar erythrodysesthesia was noticed from $5.5 \%$ to $35 \%$ with no treatment discontinuation, fatigue grade 1 or 2 up to $50 \%$, severe nausea in a few cases, and grade 3 or 4 diarrhea (3\%). One patient developed renal insufficiency and another one myocardial infarction. Three patients had to terminate their treatment due to toxicity. ${ }^{21-28}$

\section{Discussion}

The definition of NETs encompasses a group of heterogeneous tumors with peculiar clinical and biological behavior. Welldifferentiated NETs adopt an indolent course of progression and almost always are diagnosed in advanced or metastatic stage. To date, somatostatin analogs and tyrosine kinase inhibitors are used for symptom and disease control. The role of cytotoxic agents against well-differentiated NETs is not adequately defined. Since streptozocin-based chemotherapy is associated with significant toxicity, new treatment options are warranted. The alkylating agent temozolomide has a cytotoxic effect against cancer cells through DNA methylation at the $\mathrm{O}_{6}$ position of guanine. Resistance to temozolomide emerges as a result of MGMT DNA repair ability. The antimetabolite capecitabine incorporates 5-fluorodeoxyuridine triphosphate into DNA, which leads to the attenuation of MGMT repair activity through thymidylate synthase inhibition and thymidine levels reduction. Consequently, capecitabine makes MGMT more vulnerable to temozolomide cytotoxic effects. This in vitro-proved synergy of capecitabine and temozolomide was the rationale for many trials to evaluate the oral combination of capecitabine and temozolomide in the metastatic setting. ${ }^{17,29}$ pNETs seem to be more chemoresponsive (ORR: 43\%-70\%) than other NETs from GI or bronchial origin, which is translated to a median PFS of $12-18$ months. This is thought to be partially attributed to the absent or low levels of $\mathrm{O}_{6}$-MGMT deficiency which is more common in pNETs compared with non-pNETs. ${ }^{29}$ Despite the lower ORR that were observed in non-pNETs (33\%-42\%), a recent publication showed a median PFS of 22 months in this particular subgroup of tumors. ${ }^{24}$ Although there is no headto-head study between Cap/Tem and tyrosine kinase inhibitors in pNETs, the median PFS of 12-18 months achieved from Cap/Tem looks profoundly superior from the median PFS of 7-8 months produced by the tyrosine kinase inhibitors. In a study including patients pretreated with tyrosine kinase inhibitors and multiple chemotherapy agents, median PFS for all NETs was substantially lower (4.7 months). ${ }^{25}$ Median OS exceeded 2 years in the overwhelming majority of patients. The issue whether MGMT status could be a response predictor to Cap/Tem therapy was updated in the last American Society of Clinical Oncology meeting. In a trial with 144 pNETs, MGMT status was not predictive of response $(P=0.358) .{ }^{30}$ Conversely, in another study with a pNET population, MGMT methylation was correlated with PFS prolongation (16.3 vs 5.4 months). ${ }^{27}$ An interesting point is the potential role of ki-67 as predictor of the response or the outcome. In a trial from the assessed 61 pNETs, 28 tumors with ki-67>5\% showed an ORR of $64 \%$ versus $29 \%$ for the 31 pNETs with ki-67<5\%, $P=0.006 .{ }^{30}$ Likewise, another trial of NETs described an ORR of $29 \%$ in tumors with ki-67<2\% and $39 \%$ in NETs with ki-67>2\% to $20 \%{ }^{28}$ In pretreated mixed cases of pNETs and non-pNETs, PFS was not associated with ki-67. ${ }^{25}$ From the small retrospective series of patients, definite conclusions cannot be made; however, the $\mathrm{Cap} / \mathrm{Tem}$ combination seems effective regardless of primary site, MGMT status, or ki-67.

Thrombocytopenia, lymphopenia, and hand-foot syndrome were the most common side effects from the Cap/Tem combination. This regimen shows a very tolerable toxicity profile in comparison with temozolomide combinations with other drugs. For instance, the coadministration of 
temozolomide and thalidomide has resulted in a $69 \%$ of grade $3 / 4$ lymphopenia, while $10 \%$ of patients had opportunistic infections which led to therapy discontinuation. Additionally, in the studies of tyrosine kinase inhibitors, more grade 3/4 adverse events occurred than in the Cap/ Tem regimen. Grade 2 lymphopenia and grade 3 thrombocytopenia were met at a maximum value of $50 \%$ and $12 \%$, respectively in the Cap/Tem combination. ${ }^{16}$

\section{Conclusion}

Cap/Tem is an oral, well-tolerated treatment for the management of the well-differentiated NETs. The toxicity profile is superior compared with streptozocin-based regimens. Cap/Tem chemotherapy appears to be multiple times more efficacious than tyrosine kinase inhibitors and also less toxic. Taking into account that chemotherapy so far has produced poor results against non-pNET tumors, the Cap/Tem regimen proved effective in all neuroendocrine subtypes including GI non-pNETs and bronchial carcinoids. Prospective trials are needed to compare Cap/Tem with streptozocin and tyrosine kinase inhibitors in order to establish a standard of care. Since the only potential cure for patients with NETs is surgery, perhaps new trials should be designed to evaluate the impact of a neoadjuvant Cap/Tem administration.

\section{Disclosure}

The authors report no conflicts of interest in this work.

\section{References}

1. Hallet J, Law CH, Cukier M, Saskin R, Liu N, Singh S. Exploring the rising incidence of neuroendocrine tumors: a population-based analysis of epidemiology, metastatic presentation and outcomes. Cancer. 2015; 121(4):589-597.

2. Yao JC, Hassan M, Phan A, et al. One hundred years after "carcinoid": epidemiology of and prognostic factors for neuroendocrine tumors in 35,825 cases in the United States. J Clin Oncol. 2008;26(18): 3063-3067.

3. Rinke A, Müller HH, Schade-Brittinger C, et al. Placebo-controlled, double-blind, prospective, randomized study on the effect of octreotide LAR in the control of tumor growth in patients with metastatic neuroendocrine midgut tumors: a report from the PROMID Study Group. J Clin Oncol. 2009;27(28):4656-4663.

4. Caplin ME, Pavel M, Ćwikła JB, et al. Lanreotide in metastatic enteropancreatic neuroendocrine tumors. N Engl J Med. 2014;371(3): 224-233.

5. Raymond E, Dahan L, Raoul JL, et al. Sunitinib malate for the treatment of neuroendocrine pancreatic tumors. $N$ Engl J Med. 2011;364(6): 501-513.

6. Yao JC, Shah MH, Ito T, et al. Everolimus for advanced pancreatic neuroendocrine tumors. $N$ Engl J Med. 2011;364(6):514-523.

7. Dilz LM, Denecke T, Steffen IG, et al. Streptozocin/5-fluorouracil chemotherapy is associated with durable response in patients with advanced pancreatic tumours. Eur J Cancer. 2015;51(10): $1253-1262$.
8. Kouvaraki MA, Ajani JA, Hoff P, et al. Fluorouracil, doxorubicin, and streptozocin in the treatment of patients with locally advanced and metastatic pancreatic endocrine carcinomas. J Clin Oncol. 2004; 22(23):4762-4771.

9. Delaunoit T, Ducreux M, Boige V, et al. The doxorubicin-streptozocin combination for the treatment of advanced well-differentiated pancreatic endocrine carcinoma: judicious option? Eur J Cancer. 2004; 40(4):515-520.

10. Cheng PN, Saltz LB. Failure to confirm major objective antitumor activity for streptozocin and doxorubicin in the treatment of patients with advanced islet cell carcinoma. Cancer. 1999;86(6):944-948.

11. Medley L, Morel AN, Farrugia D, et al. Phase II study of single agent capecitabine in the treatment of metastatic non-pancreatic neuroendocrine tumours. Br J Cancer. 2011;104(7):1067-1070.

12. Bongiovanni A, Riva N, Calpona S, et al. Metronomic capecitabine in gastroenteropancreatic neuroendocrine tumors: a suitable regimen and review of the literature. Onco Targets Ther. 2014;(7):1919-1926.

13. Meyer T, Qian W, Caplin ME, et al. Capecitabine and streptozocin \pm cisplatin in advanced gastroenteropancreatic neuroendocrine tumors. Eur J Cancer. 2014;50(5):902-911.

14. Altimari AF, Badrinath K, Reisel HJ, Prinz RA. DTIC therapy in patients with malignant intra-abdominal neuroendocrine tumors. Surgery. 1987;102(6):1009-1017.

15. Ekeblad S, Sundin A, Janson ET, et al. Temozolomide as monotherapy is effective in treatment of advanced neuroendocrine tumors. Clin Cancer Res. 2007;13(10):2986-2991.

16. Kulke MH, Stuart K, Enzinger PC, et al. Phase II study of temozolomide and thalidomide in patients with metastatic neuroendocrine tumors. J Clin Oncol. 2006;24(3):401-406.

17. Fine RL, Fogelman DR, Schreibman SM. Effective treatment of neuroendocrine tumors with temozolomide and capecitabine. J Clin Oncol. 2005;23(Suppl 16):S4216.

18. Cohen AL, Colman H. Glioma biology and molecular markers. Cancer Treat Res. 2015;163:15-30.

19. Murakami J, Lee YJ, Kokeguchi S, et al. Depletion of O6-methylguanineDNA methyltransferase by O6-benzylguanine enhances 5-FU cytotoxicity in colon and oral cancer cell lines. Oncol Rep. 2007; 17(6):1461-1467.

20. Spiro TP, Liu L, Majka S, Haaga J, Willson JK, Gerson SL. Temozolomide: the effect of once- and twice-a-day dosing on tumor tissue levels of the DNA repair protein $\mathrm{O}(6)$-alkylguanine-DNA-alkyltransferase. Clin Cancer Res. 2001;7(8):2309-2317.

21. Strosberg JR, Fine LR, Choi J, et al. First-line chemotherapy with capecitabine and temozolomide in patients with metastatic pancreatic endocrine carcinomas. Cancer. 2011;117(2):268-275.

22. Fine RL, Gulati AP, Krantz BA, et al. Capecitabine and temozolomide (CAPTEM) for metastatic, well-differentiated neuroendocrine cancers. The Pancreas Center at Columbia University experience. Cancer Chemother Pharmacol. 2013;71(3):663-670.

23. Saif MW, Kaley K, Brennan M, Garcon MC, Rodriguez G, Rodriguez T. A retrospective study of capecitabine/temozolomide (CAPTEM) regimen in the treatment of metastatic neuroendocrine tumors (pNETs) after failing previous therapy. JOP. 2013;14(5):498-501.

24. Fine RL, Gulati AP, Tsushima D, et al. Prospective phase II study of capecitabine and temozolomide (CAPTEM) for progressive, moderately, and well-differentiated metastatic neuroendocrine tumors. Abstract 179 presented at: Gastrointestinal Cancers Symposium; January 17, 2014.

25. Peixoto RD, Noonan KL, Pavlovich P, Kennecke HF, Lim HJ. Outcomes of patients treated with capecitabine and temozolomide for advanced pancreatic neuroendocrine tumors (PNETs) and non-PNETs. $J$ Gastrointest Oncol. 2014;5(4):247-252.

26. Abbasi S, Kashashna A, Albaba H. Efficacy of capecitabine and temozolomide combination in well-differentiated neuroendocrine tumors: Jordan experience. Pancreas. 2014;43(8):1303-1305.

27. Ramirez RA, Boudreaux JP, Wang YZ, et al. Combination capecitabine/ temozolomide (CAPTEM) in patients with neuroendocrine tumors (NETs) a single institution review. J Clin Oncol. 2015;33(Suppl; abstr e15184). 
28. Spada F, Antonuzzo L, Marconcini R, et al. Chemotherapy with capecitabine plus temozolomide (CAP-TEM) in patients with advanced neuroendocrine neoplasma (NENs): an Italian multicenter retrospective analysis. J Clin Oncol. 2015;33(Suppl; abstr e15174).

29. Kulke MH, Hornick JL, Frauenhoffer C, et al. O6-methylguanine DNA methyltransferase deficiency and response to temozolomide-based therapy in patients with neuroendocrine tumors. Clin Cancer Res. 2009;15(1):338-345.
30. Strosberg JR, Cives M, Brelsford M, et al. Identification of response predictors to capecitabine/temozolomide in metastatic pancreatic neuroendocrine tumors. J Clin Oncol. 2015;33(Suppl; abstr 4099).

\section{Publish your work in this journal}

OncoTargets and Therapy is an international, peer-reviewed, open access journal focusing on the pathological basis of all cancers, potential targets for therapy and treatment protocols employed to improve the management of cancer patients. The journal also focuses on the impact of management programs and new therapeutic agents and protocols on

patient perspectives such as quality of life, adherence and satisfaction. The manuscript management system is completely online and includes a very quick and fair peer-review system, which is all easy to use. Visit http://www.dovepress.com/testimonials.php to read real quotes from published authors. 